\title{
Sinus Tachycardia, CTCAE 5.0
}

National Cancer Institute

\section{Source}

National Cancer Institute. Sinus Tachycardia, CT CAE 5.0. NCI Thesaurus. Code C146759.

A disorder characterized by a dysrhythmia with a heart rate greater than 100 beats per

minute that originates in the sinus node. 